\title{
Design of Nonlinear Robust Rotor Current Controller for DFIG Based on Terminal Sliding Mode Control and Extended State Observer
}

\author{
Guowei Cai, ${ }^{1}$ Cheng Liu, ${ }^{2}$ Deyou Yang, ${ }^{1}$ and Nantian Huang ${ }^{1}$ \\ ${ }^{1}$ School of Electrical Engineering, Northeast Dianli University, Jilin 132012, China \\ ${ }^{2}$ School of Electrical and Electronic Engineering, North China Electric Power University, Beijing 102206, China
}

Correspondence should be addressed to Cheng Liu; eeliucheng@hotmail.com

Received 8 November 2013; Revised 18 January 2014; Accepted 19 January 2014; Published 3 March 2014

Academic Editor: Shuping He

Copyright (C) 2014 Guowei Cai et al. This is an open access article distributed under the Creative Commons Attribution License, which permits unrestricted use, distribution, and reproduction in any medium, provided the original work is properly cited.

\begin{abstract}
As to strong nonlinearity of doubly fed induction generators (DFIG) and uncertainty of its model, a novel rotor current controller with nonlinearity and robustness is proposed to enhance fault ride-though (FRT) capacities of grid-connected DFIG. Firstly, the model error, external disturbances, and the uncertain factors were estimated by constructing extended state observer (ESO) so as to achieve linearization model, which is compensated dynamically from nonlinear model. And then rotor current controller of DFIG is designed by using terminal sliding mode variable structure control theory (TSMC). The controller has superior dynamic performance and strong robustness. The simulation results show that the proposed control approach is effective.
\end{abstract}

\section{Introduction}

With the development of wind generator technology, doubly fed induction generator (DFIG) has been the dominant technology used in wind power generation systems $[1,2]$. This promising technology offers many technical and economic advantages; however, DFIG easily suffers from the effect of power system disturbances [3]. Thus, in many countries, modern grid codes stipulated specifically the voltage sag and overcurrent in the rotor side converter (RSC) profile. This is commonly referred as the fault ride-through (FRT) requirement [4]. So it is extremely important to maintain current in the rotor side converter in the DFIG during the period of disturbances. The overcurrent in the rotor side converter and grid-connected operation ability of the DFIG are directly affected by the nonlinear control scheme of RSC. Therefore, it has an important practical significance for researching advanced RSC control method of this stochastic system.

At present, low voltage ride-though (LVRT) of DFIG, which is one of main content of FRT, is studied widely and many improvement approaches are provided by scholars.
However, there are seldom researchers to work on overcurrent of DFIG for improving FRT, which caused by power system disturbances. When a fault occurs in power system, overcurrent in the RSC of wind turbines will threaten the generator's security, which even lead to a serious wind turbine generators tripping accident. So it is extremely important to maintain current in the rotor side converter in the DFIG during period of disturbances. There are some means to enhance the control ability of rotor current and FRT capacity of DFIG. The schemes reported in the literatures can be divided into two categories: (1) using hardware circuit, namely, placing crowbars protection at the RSC and additional bypass resistance in the DFIG structure $[5,6]$, and (2) modifying the conventional control schemes [7-12]. The first method can improve the FRT capability of DFIG, while increasing the cost and complexity. So it is more worthy of studying by using control strategy without hardware circuit, compared with the current crowbars protection method using bypass resistance. Traditional rotor current controller for DFIG is designed on the determination model and linear control theory, such as PI control, which has a simple structure and is easy to apply. However, DFIG generation system is a typical time-varying 
dynamic system with parametric uncertainties and strongly nonlinear. The operating conditions of the system have changed all the time, so that these factors make conventional PI controller cannot meet the system requirements.

The linear system control method is based on accurate model, and it does not have the robustness with the parameters. The compensate for the shortcomings of the linear controller, the nonlinear theory is applied to control for DFIG systems. In [7], it has achieved good effect on energy storage system using mainly the sliding mode and fuzzy control; however, the determination of fuzzy control rules is complex. DFIG rotor side control through gain scheduling designed by genetic algorithm (GA) is introduced in [8], and in this work it proposes one which is based on the states feedback in order to provide the rotor current control enclosure. But GA is an optimization algorithm, which is time consuming and easy to be affected by unknown factors of the system. In [9], highorder sliding mode has been applied into control of DFIG and it has good effect. However, it is difficult to apply because it is affected by time-varying parameters, multivariable, and coupling of the actual system. Traditional SMC control has been used for DFIG and achieves good effect [10]. But it is hard to achieve the best control effect due to complex design.

The linear sliding mode surfaceis generally chosen by traditional sliding mode control. The state of the system is force to be slide according to the predetermined trajectory, and gradually converge to zero, but tracking error of state does not converge to zero in the limited time. Therefore, terminal sliding mode control is put forward by some scholars. On the basis of the sliding mode control's stability, it tries the best to improve the convergence speed of system [13]. Compared with traditional SMC, terminal sliding mode variable structure control (TSMC) has more advantages. As means of discontinuity control, TSMC with robustness, and high control precision, simple structure has been widely used in practice [13]. The sliding mode control method for linear system will be more effective. However, the wind turbine is complex and stochastic multivariable nonlinear system. As shown in above, traditional method cannot satisfy it, because traditional method is greatly affected by the disturbance and uncertainty factors. In order to compensate for the shortcomings of the linear system control method and traditional nonlinear control method, the extended state observer (ESO) is applied to design rotor current controller of DFIG $[14,15]$. The ESO in autodisturbances-rejection controller can solve the problem of the disturbance and uncertainty in wind power system $[14,15]$. Dealing with disturbance and parameter uncertainty problem, the inside and outside interference of system can be observed by ESO effectively, then compensate it through the control law, in order to obtain the linearization model by nonlinear factors being compensated dynamically.

The nonlinear controller with strong robust in the power system application is also more and more researcher's attention $[16,17]$. In order to enhance performance of rotor current controller, the novel nonlinear ESO-terminal SMC approach is introduced to design control law of rotor current controller of DFIG in this paper. The ESO is used to estimate the model error and the uncertain external disturbance and eliminate them by feedback. The controller of the rotor current of DFIG, feedback based on ESO, can easily be designed on the terminal SMC method. The proposed algorithm improves the deficiency of the traditional method. The simulation result shows that this method is simple and effective, and the rotor current of DFIG controller has stronger robustness and superior static and dynamic performance than the rotor current controller, which was designed on PI control technique.

The rest part of the paper is organized as follows. Section 2 gives brief description of ESO and terminal SMC. With dynamic behavior of grid-connected DFIG in the synchronous $d-q$ reference frame given and conventional PI controller briefly described, ESO-terminal SMC scheme is proposed, designed, and analyzed in Section 3. Section 4 presents the simulation results to demonstrate the performance of the proposed control scheme. Finally, the conclusions are made in Section 5.

\section{Design Principles of Terminal Sliding Mode Variable Structure Controller Based on ESO}

2.1. Feedback Linearization-Based ESO. ESO is the important composition of autodisturbances-rejection controller [14, 15]. The ESO is an observer which can estimate the uncertainties along with the states of the system, and make the disturbance rejected or compensated. Since the observer estimates the uncertainties as an extended state, it is designated as ESO. The $n$th order nonlinear uncertain system with an uncertainty, which suffers from some unknown external disturbance, is expressed as follows $[14,15]$ :

$$
x^{(n)}=f\left(x, x^{(1)}, x^{(2)}, \ldots, x^{(n-1)}, t\right)+w(t)+b u(t),
$$

where $f\left(x, x^{(1)}, x^{(2)}, \ldots, x^{(n-1)}, t\right)$ is unknown functions, $w(t)$ is unknown disturbances, $x$ is the measurement state variable, $u(t)$ is the control input, and $b$ is the coefficient of control input.

Let

$$
\begin{gathered}
x_{1}(t)=x(t) \\
\vdots \\
x_{n}(t)=x^{(n-1)}(t) \\
x_{n+1}(t)=f\left(x, x^{(1)}, \ldots, x^{(n-1)}, t\right)+w(t) .
\end{gathered}
$$

Then the expansion state equation of the system (1) is given by

$$
\begin{gathered}
\dot{x}_{1}(y)=x_{2}(t) \\
\dot{x}_{2}(t)=x_{3}(t) \\
\vdots \\
\dot{x}_{n}(t)=x_{n+1}(t)+b u(t) \\
\dot{x}_{n+1}(t)=h(t),
\end{gathered}
$$


where $h(t)$ is an unknown function. Then the expansion state observer can be constructed as follows:

$$
\begin{gathered}
\dot{z}_{1}(t)=z_{2}(t)-g_{1}\left(e_{01}\right) \\
\dot{z}_{2}(t)=z_{3}(t)-g_{2}\left(e_{01}\right) \\
\vdots \\
\dot{z}_{n}(t)=z_{n+1}(t)-g_{n}\left(e_{01}\right)+b u(t) \\
\dot{z}_{n+1}(t)=-g_{n+1}\left(e_{01}\right),
\end{gathered}
$$

where $z_{1}(t), \ldots, z_{n+1}(t)$ are the output of the ESO, $e_{01}=$ $z_{1}-x_{1} \cdot g_{1}\left(e_{01}\right), \ldots, g_{n+1}\left(e_{01}\right)$ all appropriately constructed the nonlinear correction function.

Then from (3) and (4), we have

$$
\begin{gathered}
\dot{e}_{01}=e_{02}-g_{1}\left(e_{01}\right) \\
\dot{e}_{02}=e_{03}-g_{2}\left(e_{01}\right) \\
\vdots \\
\dot{e}_{0 n}=e_{0 n+1}-g_{n}\left(e_{1}\right)+b u(t) \\
\dot{e}_{0 n+1}=-h(t)-g_{n+1}\left(e_{01}\right),
\end{gathered}
$$

where $e_{0 i}=z_{i}-x_{i},(i=1, \ldots, n+1)$.

For an arbitrarily changing $h$ in a certain range, it is proven [14] that if the nonlinear continuous functions $g_{1}\left(e_{01}\right), \ldots, g_{n+1}\left(e_{01}\right)$ are chosen, then system equation (5) is stable with respect to the origin. This means that, with appropriate choices of functions $g_{1}\left(e_{01}\right), \ldots, g_{n+1}\left(e_{01}\right)$, the states of system equation (4) can track the corresponding states of system equation (3); that is,

$$
\begin{aligned}
z_{1}(t) & \longrightarrow x_{1}(t), \ldots, z_{n}(t) \longrightarrow x_{n}(t), \ldots, z_{n+1}(t) \\
& \longrightarrow x_{n+1}(t) .
\end{aligned}
$$

According to the definitions in (2), $x_{n+1}(t)$ is the summation of the unknown function $f\left(x, x^{(1)}, x^{(2)}, \ldots, x^{(n-1)}, t\right)$ and the external disturbance $w(t)$ in (1). Thus, the output $z_{n+1}(t)$ in system equation (4) can have the real-time estimation for $x_{n+1}(t)$ as long as a set of functions $g_{1}\left(e_{01}\right), \ldots, g_{n+1}\left(e_{01}\right)$ can be found to meet the conditions. Since $x_{n+1}(t)$ is an extended state defined in addition to the necessary states, $x_{1}(t), \ldots, x_{n}(t)$, to describe the dynamics in (1), the nonlinear system equation (4) is hence called the ESO. It is obvious that the ESO is one order higher than that of the system to be observed.

The control variable is selected as follows:

$$
u(t)=\frac{u_{0}(t)-x_{n+1}}{b_{0}}=\frac{u_{0}(t)-z_{n+1}}{b_{0}} .
$$

2.2. Terminal Sliding Model Variable Structure Control. Taking into account the tracking error of ESO and the limiting feature of controller, $u_{0}(t)$ is the primary input of pseudolinear systems after the feedback linearization, which can be designed by using global fast robust terminal sliding mode control.

The so-called terminal sliding mode control is the new terminal sliding surface, which contains nonlinear function, making the tracking error be able to converge to zero in finite time [13].

The traditional form of fast terminal sliding mode is as follows:

$$
s=\dot{x}+\beta x^{q / p}=0,
$$

where $x \in R$ is the state variable, $\beta>0$, and $p$ and $q(p>q)$ are positive odd number.

Due to the nonlinear part $\beta x^{q / p}$ which is introduced, the convergence speed is improved, but the convergence time of terminal sliding mode control is not the fastest. Therefore, a new global fast terminal sliding modal is proposed in [13].

The terminal SMC form is as follows:

$$
\dot{s}+\alpha s+\beta s^{q / p}=0
$$

where $\alpha, \beta>0$.

The sliding mode control law can be designed from (9):

$$
u_{0}=-\sum_{i=1}^{n-1} c_{i} x_{i+1}-\alpha s-\beta s^{q / p} .
$$

\section{The Proposed Rotor Current Control Approach}

3.1. Mathematical Modeling of the DFIG. The model of DFIGbased wind turbines is studied in $[18,19]$. The equivalent circuit of a DFIG represented in the synchronous $d$ - $q$ reference frame is shown in Figure 1.

The stator and rotor voltage in the synchronous $d-q$ reference frame can be given as

$$
\begin{gathered}
u_{q, d s}=R_{s} i_{q, d s}+\frac{d \psi_{q, d s}}{d t} \pm \omega_{s} \psi_{d, q s}, \\
u_{q, d r}=R_{r} i_{q, d r}+\frac{d \psi_{q, d r}}{d t} \pm\left(\omega_{s}-\omega_{r}\right) \psi_{d, q r},
\end{gathered}
$$

where $U$ is the voltage vector, $I$ is the current vector, and $\psi$ is the flux linkage vector, which are shown in Figure 1. $u$ is the voltage, $i$ is the current, $\psi$ is the flux linkage, and $R$ is the resistance. The indices indicate the direct and quadrature components of the reference frame and indicate stator and rotor quantities, respectively. $\omega_{s}$ is synchronous angular frequency. $\omega_{r}$ is rotor angular frequency.

The stator and rotor flux linkage can be given as [19]

$$
\begin{aligned}
& \psi_{q, d s}=L_{s} i_{q, d s}+L_{m} i_{q, d r}, \\
& \psi_{q, d r}=L_{m} i_{q, d s}+L_{r} i_{q, d r},
\end{aligned}
$$

where $L_{s}=L_{\sigma s}+L_{m}$ and $L_{r}=L_{\sigma r}+L_{m}$ are selfinductances of stator and rotor windings, respectively. $L_{m}$ is mutual inductance. $L_{\sigma s}$ and $L_{\sigma r}$ are the stator and rotor leakage inductances, respectively. 


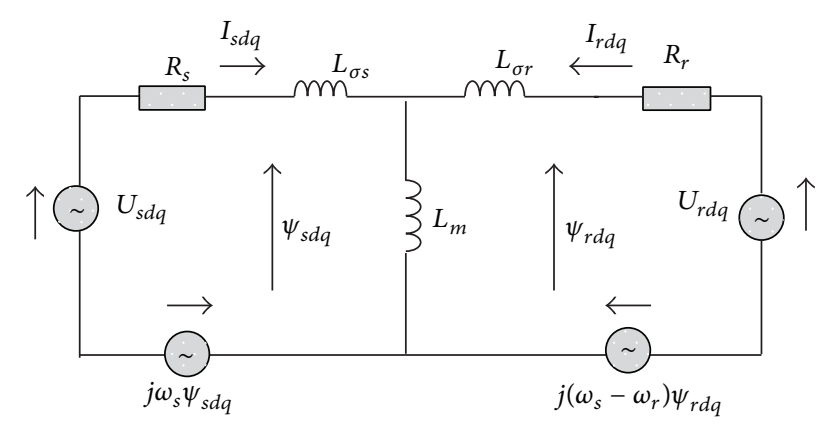

FIGURE 1: Equivalent circuit of a DFIG in the synchronous $d-q$ reference frame.

In order to reduce the destructiveness of DFIG overcurrent in the rotor winding or large overvoltage in the $d c$-link capacitor, it is necessary to consider the dynamic process of stator excitation current in the control strategy of DFIG. Using (12), the rotor flux linkage can be expressed as

$$
\psi_{q, d s}=L_{m} I_{m o r, s}=L_{s} i_{q, d s}+L_{m} i_{q, d r}
$$

where $I_{m o s}$ and $I_{m o r}$ are the stator and rotor current intermediate variables, respectively.

Substituting (13) into (11), the voltage is obtained as

$$
\begin{gathered}
u_{q, d s}=R_{s} i_{q, d s}+L_{m} \frac{d I_{m o r, s}}{d t} \pm \omega_{s} \psi_{d, q s}, \\
u_{q, d r}=R_{r} i_{q, d r}+\frac{L_{m}^{2}}{L_{s}} \frac{d I_{m o r, s}}{d t}+\xi L_{r} \frac{d i_{q, d r}}{d t} \pm \omega_{s} \psi_{d, q r},
\end{gathered}
$$

where $\xi=1-L_{m}^{2} / L_{r} L_{s}$ is leakage factor.

Based on (14), the instantaneous current can be expressed as

$$
\frac{d I_{m o r, s}}{d t}=\frac{\left(u_{q, d s}-R_{s} i_{q, d s} \mp \omega_{s} \psi_{d, q s}\right)}{L_{m}} .
$$

Substituting (16) into (15), the instantaneous rotor current can be expressed with respective $d$-q-axis as

$$
\begin{aligned}
\frac{d i_{d r}}{d t}= & \frac{u_{d r}}{\xi L_{r}}-\frac{R_{r} i_{d r}}{\xi L_{r}}+\frac{\left(\omega_{s}-\omega_{r}\right) \psi_{q r}}{\xi L_{r}} \\
& -\frac{L_{m}\left(u_{d s}-R_{s} i_{d s}+\omega_{s} \psi_{q s}\right)}{\xi L_{r} L_{s}}, \\
\frac{d i_{q r}}{d t}= & \frac{u_{q r}}{\xi L_{r}}-\frac{R_{r} i_{q r}}{\xi L_{r}}-\frac{\left(\omega_{s}-\omega_{r}\right) \psi_{d r}}{\xi L_{r}} \\
& -\frac{L_{m}\left(u_{q s}-R_{s} i_{q s}-\omega_{s} \psi_{d s}\right)}{\xi L_{r} L_{s}} .
\end{aligned}
$$

When power system failure occurred, the controller is designed based on (17). Compared with traditional controller, the $L_{m}\left(u_{d s}-R_{s} i_{d s}+\omega_{s} \psi_{q s}\right) / L_{s} L_{r} \xi$ and $L_{m}\left(u_{q s}-R_{s} i_{q s}-\right.$ $\left.\omega_{s} \psi_{d s}\right) / L_{s} L_{r} \xi$ are nonlinear disturbances, which need to be compensated:

$$
\begin{gathered}
\frac{d i_{d r}}{d t}=\frac{u_{d r}}{\xi L_{r}}-\frac{R_{r} i_{d r}}{\xi L_{r}}+\Delta u_{d r}, \\
\Delta u_{d r}=\frac{\left(\omega_{s}-\omega_{r}\right) \psi_{q r}}{\xi L_{r}}-\frac{L_{m}\left(u_{d s}-R_{s} i_{d s}+\omega_{s} \psi_{q s}\right)}{\xi L_{r} L_{s}}, \\
\frac{d i_{q r}}{d t}=\frac{u_{q r}}{\xi L_{r}}-\frac{R_{r} i_{q r}}{\xi L_{r}}+\Delta u_{q r}, \\
\Delta u_{q r}=-\frac{\left(\omega_{s}-\omega_{r}\right) \psi_{d r}}{\xi L_{r}}-\frac{L_{m}\left(u_{q s}-R_{s} i_{q s}-\omega_{s} \psi_{d s}\right)}{\xi L_{r} L_{s}},
\end{gathered}
$$

where the $\Delta u_{q r}, \Delta u_{d r}$ are disturbance terms of the current controller. This part is chosen as a perturbation, partly because more parameters and nonlinearity are in this part, and it affects the system greatly. We should try to eliminate it in actual.

Using (18) and (19), the terminal SMC controller can be designed.

\subsection{Proposed Terminal SMC Controller Based on ESO.} Figure 2 shows the schematic diagram of the proposed rotor current controller. The principle of new current controllers for a grid-connected DFIG system is presented in Figure 2.

In a terminal SMC design, the SMC law and switching function are mainly considered [19]. Since the $d$ - and $q$-axis rotor current is designed similarly when a terminal SMC is designed, the only difference between control objects is their parameters. The terminal SMC design of the $d$-axis rotor current is taken for an explanation. Figure 2 shows the control structure of the new terminal SMC applied in the RSC. The same control structure can be used in the grid side converter (GSC) too.

Based on (18), the variations $i_{d r}, u_{d r}$ can be defined as state and input variations, respectively. According to the principle of the conventional PI control for a grid-connected DFIG, two forward channels are designed in the inner current control loops of $d$ - and $q$-axis rotor current. As a result, the controller of $d$ - and $q$-axis rotor current is designed, respectively.

Step 1 (designing of ESO). With the $d$-axis rotor current, for example, a coordinate transformation is selected as follows:

$$
\begin{gathered}
x_{1}=\int_{0}^{t}\left(i_{d r}(\tau)-i_{d r}^{*}(\tau)\right) d \tau, \\
x_{2}=i_{d r}(t)-i_{d r}^{*}(t),
\end{gathered}
$$

where $i_{d r}^{*}$ is the given value of reference current and $i_{d r}$ is the given value of actual current.

By differentiating on both sides of (21), (22) can be obtained as follows:

$$
\frac{d x_{2}}{d t}=\frac{d i_{d r}}{d t}=f_{1}(x)+g_{1} u_{d r}=v_{1}
$$




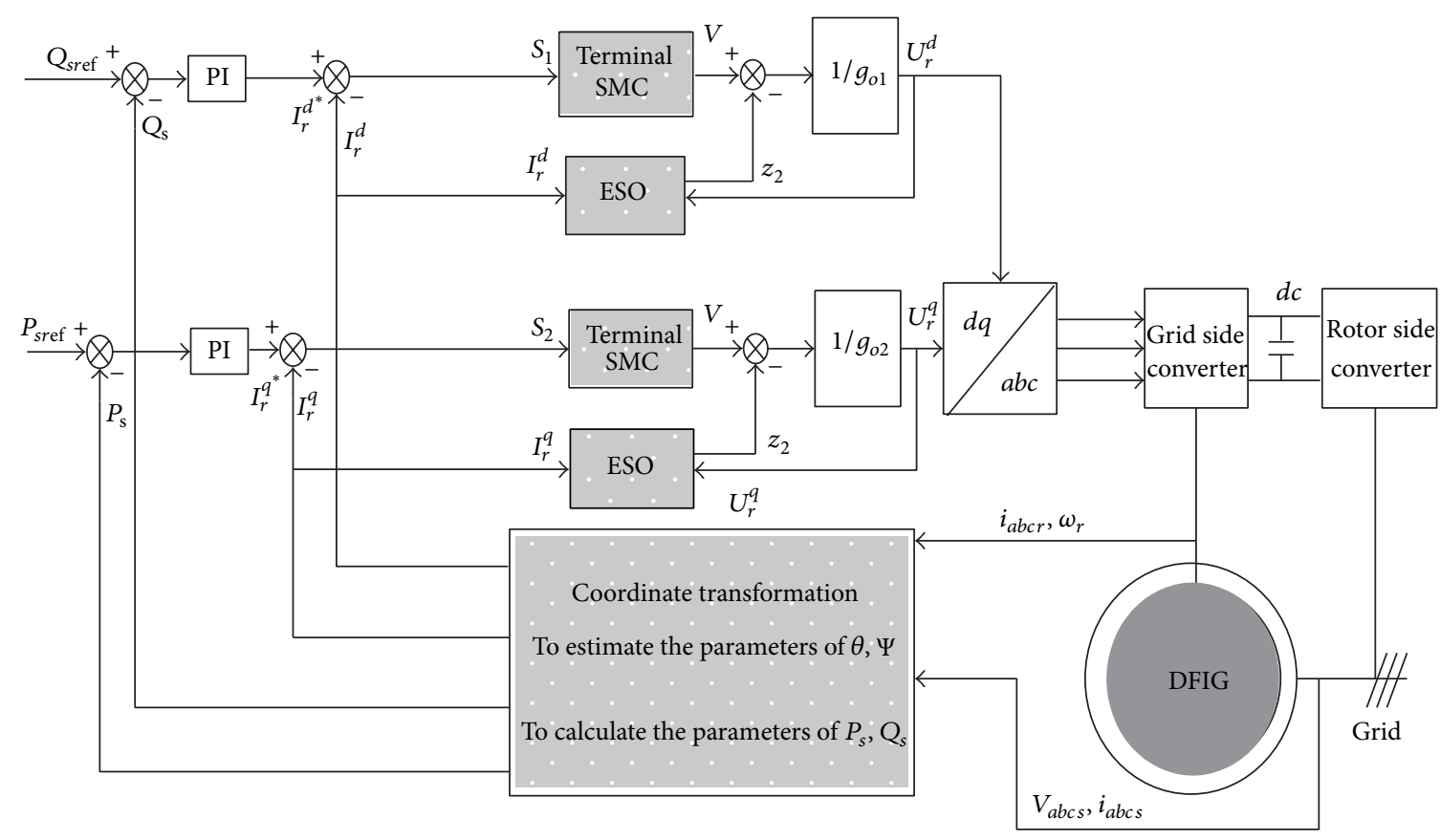

FIGURE 2: Schematic diagram of proposed rotor current controller for a grid-connected DFIG system.

where

$$
\begin{gathered}
f_{1}(x)=-\frac{R_{r} i_{d r}}{\sigma L_{r}}+\frac{\left(\omega_{s}-\omega_{r}\right) \psi_{q r}}{\xi L_{r}} \\
-\frac{L_{m}\left(u_{d s}-R_{s} i_{d s}+\omega_{s} \psi_{q s}\right)}{\xi L_{r} L_{s}} \\
=-\frac{R_{r} i_{d r}}{\xi L_{r}}+\Delta u_{d r}, \\
\Delta u_{d r}=\frac{\left(\omega_{s}-\omega_{r}\right) \psi_{q r}}{\varsigma L_{r}}-\frac{L_{m}\left(u_{d s}-R_{s} i_{d s}+\omega_{s} \psi_{q s}\right)}{\xi L_{r} L_{s}}, \\
g_{1}=\frac{1}{\xi L_{r}} .
\end{gathered}
$$

The nonlinear factors $\psi_{q r}, \psi_{q s}, \omega_{s}$, and $\omega_{r}$ are contained in $f_{1}(x)$ and those unknown parameters are difficult to be obtained.

Using ESO to do feedforward compensation for the disturbance term of the controller $\left(\Delta u_{q r}, \Delta u_{d r}\right)$ in this paper, the equation contains control input, which contains the nonlinear factors in this paper. follows:

The second-order ESO for system can be expressed as

$$
\begin{gathered}
\dot{z}_{1}=z_{2}-\beta_{01} f a l\left(z_{1}-i_{d r}(t), \alpha_{1}, \delta\right)+b_{0} u \\
\dot{z}_{2}=-\beta_{02} f a l\left(z_{1}-i_{d r}(t), \alpha_{1}, \delta\right)
\end{gathered}
$$

where $i_{d r}(t)$ is observable. fal function is the continuous power law function with linear segment near the origin. It avoids the high frequency chattering phenomenon.
The uncertain factors can be dynamically compensated by $z_{2}$. $\beta_{1}, \beta_{2}$, and $\delta$ are adjustable parameters.

The nonlinear function is defined as follows:

$$
f a l= \begin{cases}\frac{\varepsilon}{\delta^{1-\alpha}}, & |\varepsilon| \leq \delta, \\ |\varepsilon|^{\alpha} \operatorname{sgn}(\varepsilon), & |\varepsilon|>\delta,\end{cases}
$$

where $\varepsilon, \alpha$, and $\delta$ are control parameters and sgn is symbol function. $\delta>0,0<\alpha<1$ are important property of the function.

As stated earlier, the ESO is an observer which can estimate the uncertainties along with the states of the system, and make the disturbance rejected or compensated:

$$
\begin{aligned}
& \frac{d i_{d r}}{d t}=\frac{u_{d r}}{\xi L_{r}}-\frac{R_{r} i_{d r}}{\xi L_{r}}+\Delta u_{d r}=v_{d 1}=z_{2 d}+g_{1} u_{d r} \\
& \frac{d i_{q r}}{d t}=\frac{u_{q r}}{\xi L_{r}}-\frac{R_{r} i_{q r}}{\xi L_{r}}+\Delta u_{q r}=v_{q 1}=z_{2 q}+g_{1} u_{q r}
\end{aligned}
$$

where $v_{d 1}$ and $v_{q 1}$ are precontrol variables, $z_{2 d}$ and $z_{2 q}$ are extended variables of $d$ - and $q$-axis, $v_{d 1}=z_{2 d}+$ $u_{d r} /\left(\xi L_{r}\right), v_{q 1}=z_{2 q}+u_{q r} /\left(\xi L_{r}\right), z_{2 d}$ should track $\Delta u_{d r}$, and $z_{2 q}$ should track $\Delta u_{q r}$.

The disturbances $\Delta u_{d r}, \Delta u_{q r}$ are compensated by ESO in (26) and (27); then two first-order systems without disturbances are given.

Step 2 (construction of sliding surface). The control goal of the inner current control loops of $d$ - and $q$-axis rotor current is to make sure that the actual current should track their references as closely as possible. Consequently, in order to maintain the enhanced transient response and minimize 
the steady-state error, the switching surfaces can be selected as follows:

$$
s(t)=c_{1} x_{1}+x_{2},
$$

where $s(t)$ is switching function of the sliding surface, which represents $d q$ axis vector, and $c_{1}$ is positive control gains, $c>$ 0 .

By differentiating (28) and combining with (20), (21) is as follows:

$$
\frac{d s(t)}{d t}=c_{1} \frac{d x_{1}}{d t}+\frac{d x_{2}}{d t}=c_{1} \cdot\left(i_{d r}-i_{d r}^{*}\right)+\frac{d i_{d r}}{d t} .
$$

According to (9), (22), and (29), it can be obtained as

$$
\frac{d s(t)}{d t}=c_{1} \cdot x_{2}+v_{1}=-\alpha s-\beta s^{q / p} .
$$

According to the global fast terminal sliding mode as (9), the virtual control variable can be obtained:

$$
v_{1}=-c_{1} x_{2}-\alpha s-\beta s^{q / p} .
$$

Terminal SMC is tracking trajectory, and the terminal SMC strategy with variable control structure can solve the steady-state and dynamically state error problem introduced by the external disturbances. The disturbance can be disposed, and it is more suitable for processing rotor current control of DFIG compared to other method.

Step 3 (selection of terminal SMC law). In order to weaken the chattering when state variables rapidly approaching the sliding surface, $\beta s^{q / p}$ is adopted. We can adjust the parameters of $c_{1}, \alpha, \beta$ and to ensure that terminal SMC signal quality and rapid convergence.

The nonlinear factors $\left(\Delta u_{d r}, \Delta u_{q r}\right)$ in (22) should be tracked and compensated by $z_{2}$ of ESO. Based on (22) and (26), it can be expressed as follows:

$$
\frac{d x_{2}}{d t}=z_{2}+g_{1} u
$$

Based on (22) and (32), it can be expressed as follows:

$$
v_{1}=z_{2}+g_{1} u \text {. }
$$

So far, control law can be defined as follows:

$$
u=-\frac{z_{2}-v_{1}}{g_{1}}
$$

where $u=u_{d r}, z_{2}$ is extended variable, $g_{1}=1 / \xi L_{r}$.

The schematic diagram of proposed terminal sliding mode controller based on ESO (T-SMCE) is shown in Figure 3, which is the content extended of Figure 2.

Design steps are shown in Figure 4.

\section{Simulation Results}

4.1. Test System Description. In order to verify the validity of the proposed method, simulations of the proposed control scheme for a DFIG-based wind power generation system were carried out. It compares FRT capabilities of the proposed rotor current controller with the conventional PI controller. A $2 \mathrm{MW}$ DFIG in a wind farm is connected to the transmission system through a $20 \mathrm{~km}$ distribution cable. The DFIG is rated at $2 \mathrm{MW}$ with its parameters given in Table 1 . The nominal converter $d c$-link voltage was set at $1.2 \mathrm{kV}$. The parameters of terminal SMC, PI, and ESO are given in Tables 2, 3, and 4, respectively. The specific method of determining parameters can be found in [14].

The rotor current will rise rapidly and more exceed the rate value, if there is a fault at some points inside the transmission system. Thus DFIG must be maintained to a sustained grid-connected until the fault is cleared. The control method is mainly studied in this paper, which is to reduce rotor overcurrent of DFIG under power grid disturbances. Therefore, the outer power control loops of rotor side and grid side converters are constant. The mechanical parts of wind turbine are simulated based on the optimal power-speed curve [20], in order to get an accurate comparison between different current controllers.

\subsection{Comparative Studies}

Case 1 (the comparison of different control strategies under three-phase short-circuit fault). Assume that a three-phase short-circuit fault occurs in high voltage side bus of DFIG step-up transformer at $1 \mathrm{~s}$ and the failure lasts for $0.12 \mathrm{~s}$. At the condition that the proposed rotor current controller has or not, we compare the voltage of grid-connected, the rotor current and electromagnetic torque of DFIG's response to three-phase short-circuit fault respectively in Figures 5-8. The conventional and proposed methods are shown with point line and solid line, respectively.

The overcurrent in the rotor side converter is greatly weakened under the three-phase short-circuit fault. As shown in Figures 5 and 6, its recovery is more smooth. It has a short adjusting time and it can be fast recovery to steady. So it shows that the rotor current can be effectively controlled by ESO-terminal SMC, compared with conventional PI control scheme. It can reduce overcurrent in the rotor side converter under fault. The oscillation of current needs to be quelled with a long time, using conventional PI controller. But when ESO-terminal SMC is adopted, the current responses rapidly and smoothly. The drastic change of electromagnetic torque and voltage of grid-connected under power grid fault is reduced by proposed controller. There is not a large transient pulse value. The impact of the mechanical stress of the wind generator rotor system is effectively decreased. The working life of mechanical system is extended.

The possibility that a serious wind turbine generators tripping accident caused by fault is reduced. Enhanced transient performances are similar to the conventional PI. Under power system fault, the proposed approach reduced threat for generator security operation caused by the overcurrent in the rotor side converter for wind turbine. It can enhance the control ability of the rotor current and improve the stability and the grid-connected operation ability of the wind turbines. 


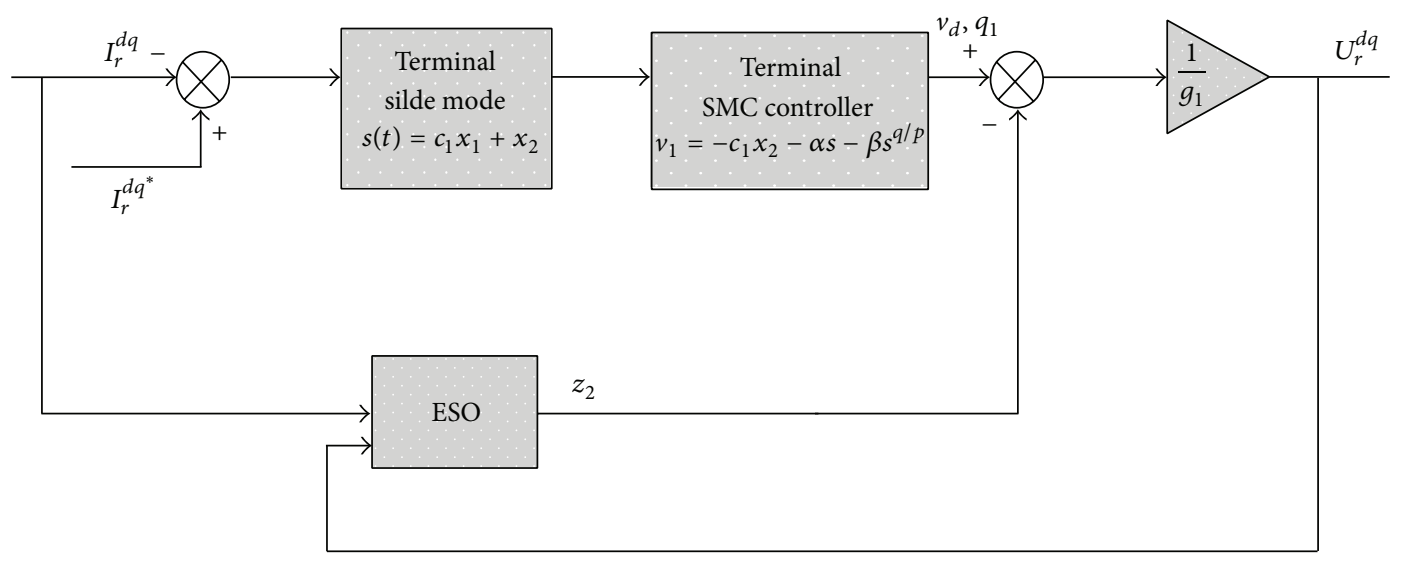

FIGURE 3: Schematic diagram of proposed terminal SMC based on ESO.

TABLE 1: Parameters of the simulated DFIG system.

\begin{tabular}{lc}
\hline Parameters & Value \\
\hline Rated power & $2 \mathrm{MW}$ \\
Line-to-line voltage & $690 \mathrm{~V}$ \\
Stator frequency & $50 \mathrm{~Hz}$ \\
$R_{s}$ & $0.01 \mathrm{p} . \mathrm{u}$. \\
$R_{r}$ & 0.01 p.u. \\
$L_{s}$ & 0.1 p.u. \\
$L_{r}$ & 0.1 p.u. \\
$L_{m}$ & 3.5 p.u. \\
Pole pairs & 2 \\
Acceleration time constant & $0.9408278 \mathrm{~s}$ \\
\hline
\end{tabular}

TABLE 2: Control parameters of terminal SMC regulator.

\begin{tabular}{lc}
\hline Parameters & Value \\
\hline$\alpha$ & 150 \\
$\beta$ & 50 \\
$c_{1}$ & 50 \\
\hline
\end{tabular}

The superiority of the designed controller is verified in this paper.

Case 2 (the comparison of different control strategies under load shedding). When system is in the steady-state operation, a load shedding fault occurs, causing a step response, wherein the active power load in power grid suddenly sags $60 \%$ at $1 \mathrm{~s}$. The voltage of grid-connected, the rotor current, and electromagnetic torque of DFIG dynamic response to load shedding without and with the proposed rotor current controller are compared in Figures 9, 10, 11, and 12. The conventional and proposed method is shown with point line and solid line, respectively.

As shown in Figures 9-12, under the load shedding, the amplitude of overcurrent in the rotor side converter is greatly weakened. Compared with PI, the transition process is faster and more smooth. The proposed control has a short adjusting time. As a result, rotor current can be effectively
TABLE 3: Control parameters of PI regulator.

\begin{tabular}{lc}
\hline Parameters & Value \\
\hline$K_{p}$ & 0.0499 \\
$K_{i}$ & 0.0128 \\
\hline
\end{tabular}

TABLE 4: Control parameters of ESO regulator.

\begin{tabular}{lc}
\hline Parameters & Value \\
\hline$\beta_{01}$ & 100 \\
$\alpha_{1}$ & 0.5 \\
$\delta_{1}$ & 0.0016 \\
$\beta_{02}$ & 300 \\
$\alpha_{2}$ & 0.25 \\
$\delta_{2}$ & 0.0016 \\
\hline
\end{tabular}

controlled by improved ESO-terminal SMC scheme. Under power grid fault, the drastic change of electromagnetic torque and voltage of grid-connected are reduced by proposed controller, respectively. The large transient pulse value is not appearing. The impact of the mechanical stress of the wind turbine rotor system is effectively reduced and also extends the working life of mechanical system. The possibility of the serious wind turbine generators tripping accident is decreasing. It enhances the FRT of DFIG. The superiority of the designed controller is verified in this paper.

4.3. The Comparison Analysis of Computation Time under Different Controller. In order to compare original PI method with the proposed method about computation time analysis objectively, the following discussion is carried out. Due to DFIG which has overcurrent protection when the amplitude of overcurrent in the rotor side converter achieves protection threshold, it will trigger protection and seriously may lead to a wind turbine generators tripping accident for DFIG. As shown in Figures 5-12 under Cases 1 and 2, the original PI control can meet the basic requirements, but a serious wind turbine generators tripping accident is easy to be caused by the larger overcurrent amplitude. However, rotor overcurrent 


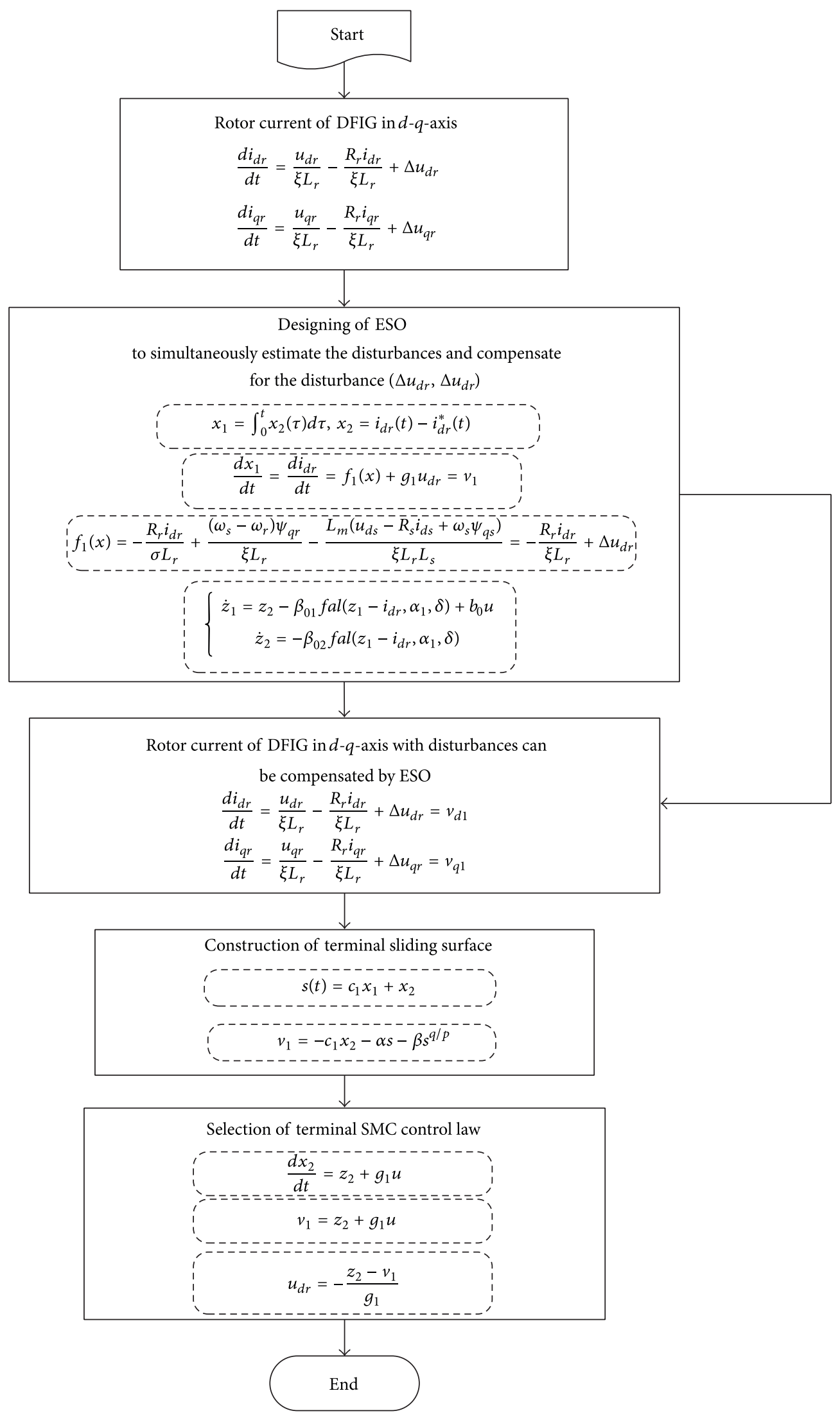

FIGURE 4: Flow diagram of proposed terminal SMC based on ESO. 


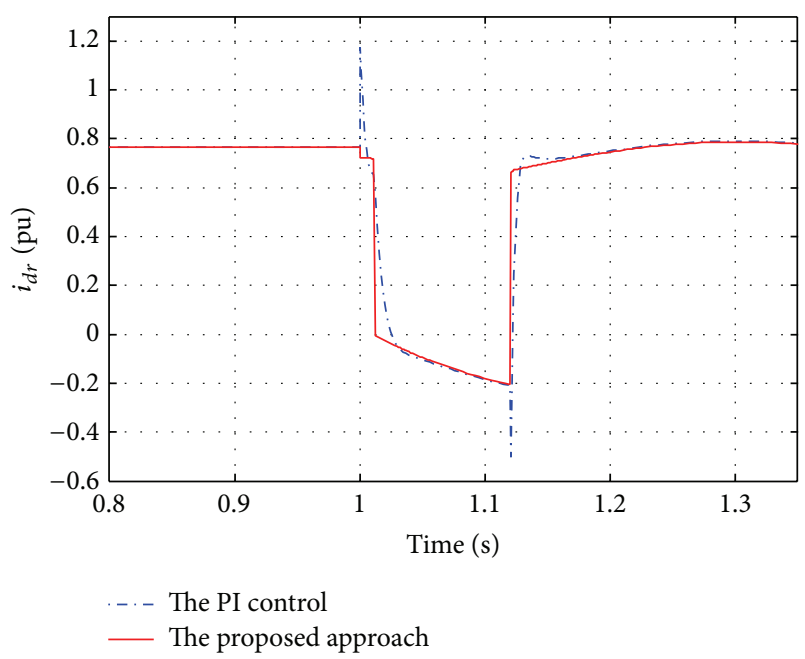

FIGURE 5: The rotor current curve of a DFIG in the direct axis.

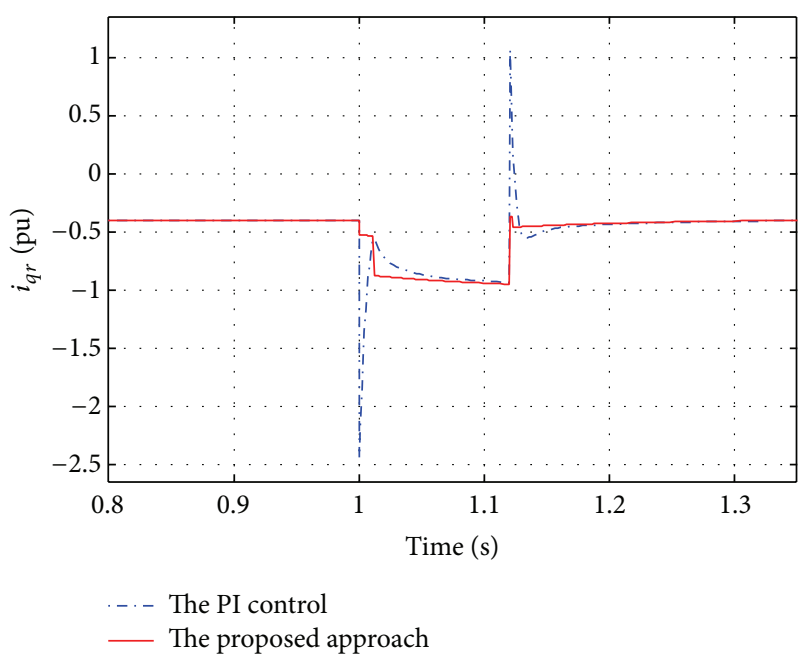

FIGURE 6: The rotor current curve of a DFIG in the quadrature axis.

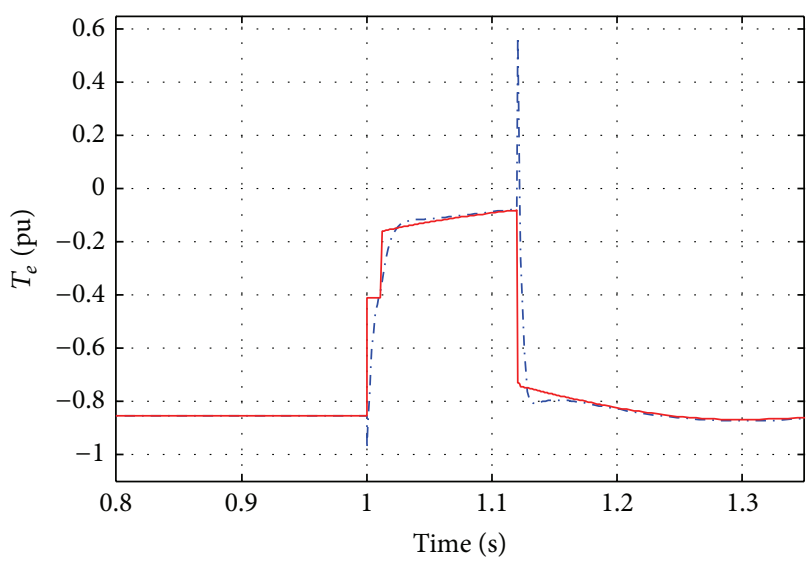

. - . - The PI control

_ The proposed approach

FIGURE 7: The electromagnetic torque curve of DFIG.

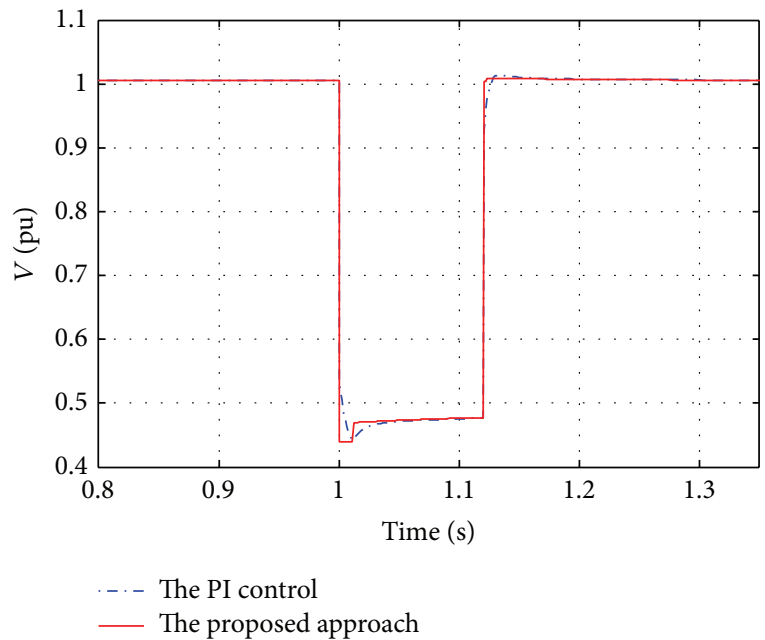

FIGURE 8: The voltage curve of grid-connected.

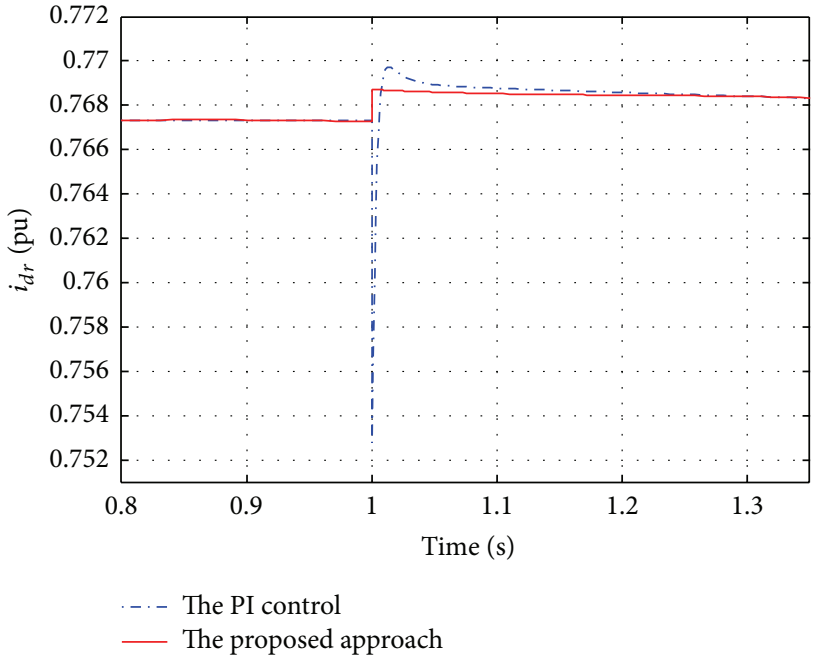

FIGURE 9: The rotor current curve of DFIG in the direct axis.

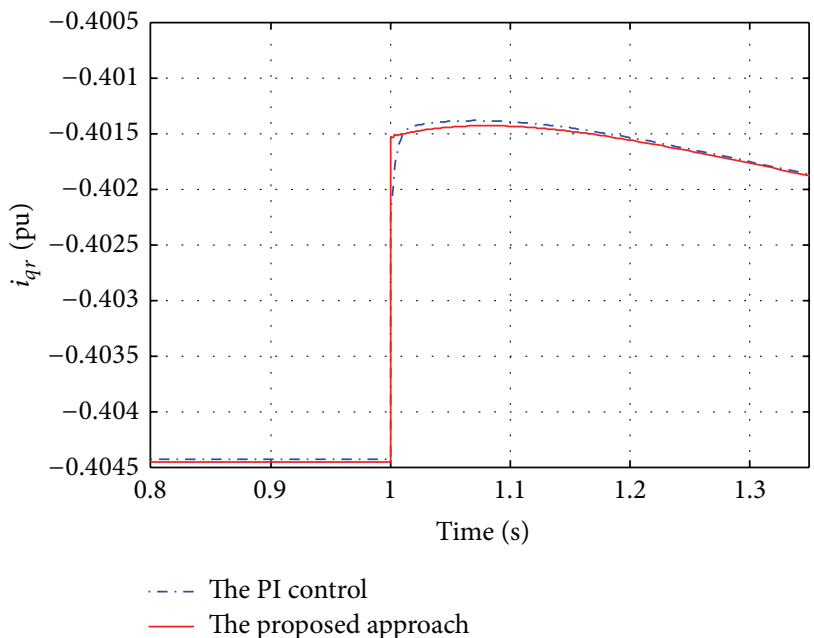

FIGURE 10: The rotor current curve of DFIG in the quadrature axis. 


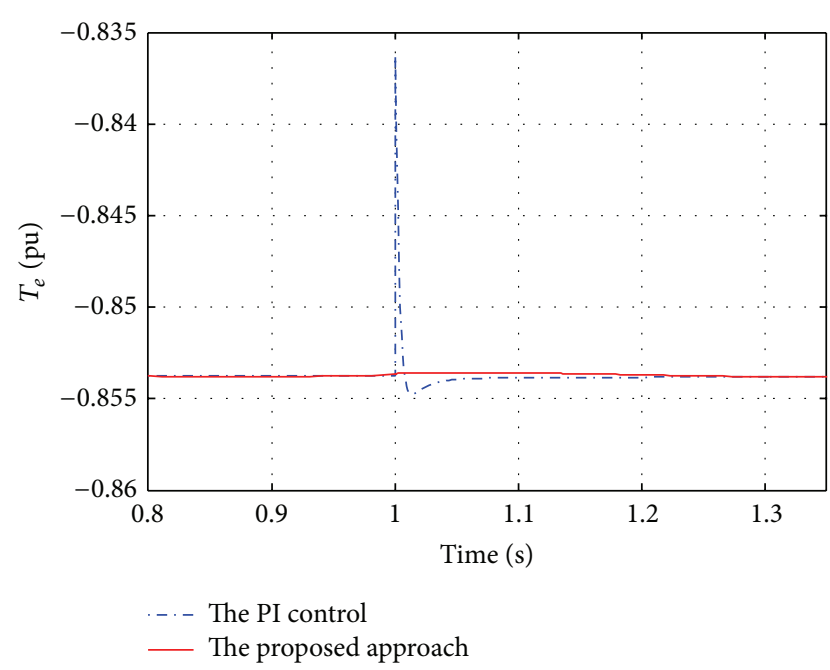

FIGURE 11: The electromagnetic torque curve of DFIG.

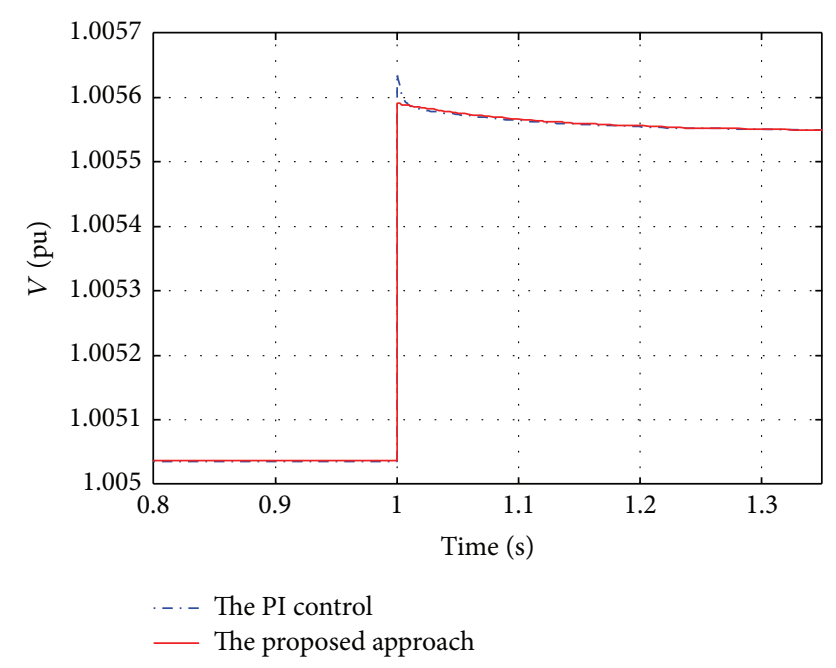

FIGURE 12: The voltage curve of grid-connected.

can be effectively controlled by improved ESO-terminal SMC scheme. The computation time of PI and proposed method for Case 1 is $2.1 \mathrm{~s}$ and $2.7 \mathrm{~s}$, respectively. For Case 2, they are $1.7 \mathrm{~s}$ and $2.4 \mathrm{~s}$, respectively. So computational burden of the proposed method is increased. However, under Cases 1 and 2, protection did not trigger by two kinds of control methods, and they can ensure the normal operation of DFIG. The feasibility and effectiveness of the designed controller are verified in this paper. The computation time of proposed method can satisfy the operating requirements and ensure the control effect.

In addition, total time taken from the control start to the standard values is defined as $t_{\text {total }}$. The $t_{\text {total }}$ of two kinds of control method is shown in Tables 5 and 6 and Figure 13. It shows that the $t_{\text {total }}$ is basically the same for two methods under Cases 1 and 2 .

Compared with the original PI control, the proposed method increased the computational burden. However, the
TABLE 5: The comparison analysis of $t_{\text {total }}$ of Case 1 under different controller.

\begin{tabular}{lcc}
\hline Parameters & PI & The proposed approach \\
\hline$i_{d r}$ & 1.26 & 1.26 \\
$i_{q r}$ & 1.21 & 1.21 \\
$T_{e}$ & 1.22 & 1.22 \\
$u$ & 1.13 & 1.14 \\
\hline
\end{tabular}

TABLE 6: The comparison analysis of $t_{\text {total }}$ of Case 2 under different controller.

\begin{tabular}{lcc}
\hline Parameters & PI & The proposed approach \\
\hline$i_{d r}$ & 1.28 & 1.28 \\
$i_{q r}$ & 1.29 & 1.29 \\
$T_{e}$ & 1.27 & 1.27 \\
$u$ & 1.31 & 1.32 \\
\hline
\end{tabular}

influence on the system caused by nonlinear factors is reduced. The increasing logic judge for DFIG caused by overshoot is reduced. Thus the computational burden of the proposed method is decreasing. So the $t_{\text {total }}$ are basically the same for two methods, as shown in Tables 5 and 6 and Figure 13. As shown in the above, the proposed method can satisfy the engineering requirement.

4.4. The Comparison of Controller Characteristics under Different Load Shedding Proportion. In the simulation, a load shedding fault is happened, causing a step response with the active power load in power grid suddenly drops $10 \%, 30 \%, 60 \%$, and $90 \%$ at $1 \mathrm{~s}$, respectively. The dynamic responses of DFIG in rotor current under different load shedding proportion with the proposed ESO-terminal SMC are compared in Figure 14.

As shown in Figure 14, with the load shedding proportion increasing, the adjusting time is growing longer and current amplitude is larger. But they are recovery to stability at last. Corresponding to the different load shedding proportion, the overcurrent in the rotor side converter reaches $1.26 \%, 0.742 \%$, $0.371 \%$, and $0.124 \%$, respectively. Although the load shedding proportion is different, the transient pulse values are almost the same. So it has a good adaptability and robustness for this controller under different load shedding proportion. As a result, when power system failure occurs, the rotor current can be effective controlled by ESO-terminal SMC. It can be improved by the proposed controller under different load shedding proportion. The superiority of the designed controller is verified in this paper.

4.5. The Influence of the System Performance Caused by Parameter Variation. In order to validate the influence of the experiment results caused by $\alpha, \beta$, and $c_{1}$, the rotor current of DFIG under different $\alpha, \beta$, and $c_{1}$ is analyzed in Figures $15-17$, respectively. The $\alpha$ is 50,150, and 500, respectively. As shown in Figure 15, the larger the $\alpha$, the faster the adjusting speed for current in general. As shown in Figure 15, when $\alpha$ is enough small, the feature of the system can also be 


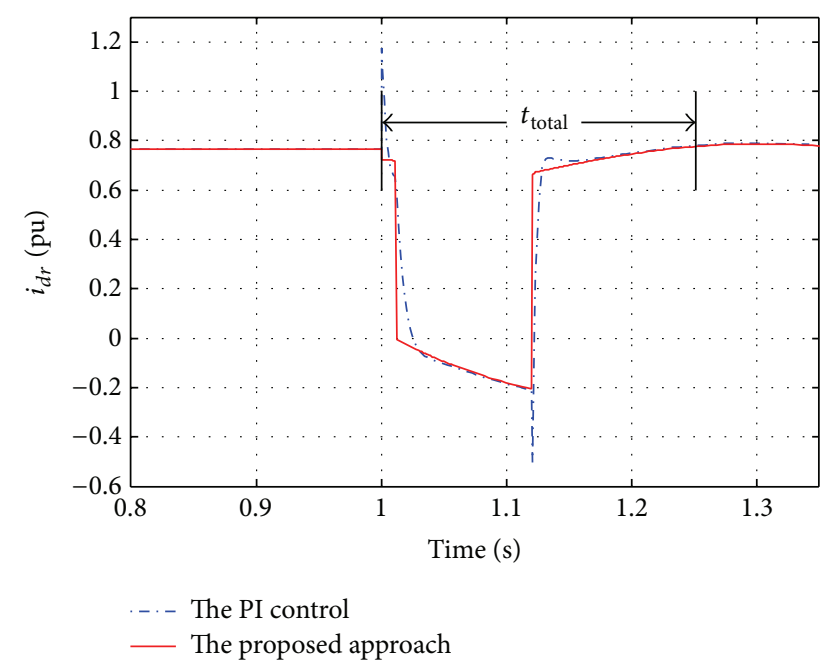

FIGURE 13: The rotor current curve of a DFIG in the direct axis under three-phase short circuit fault.

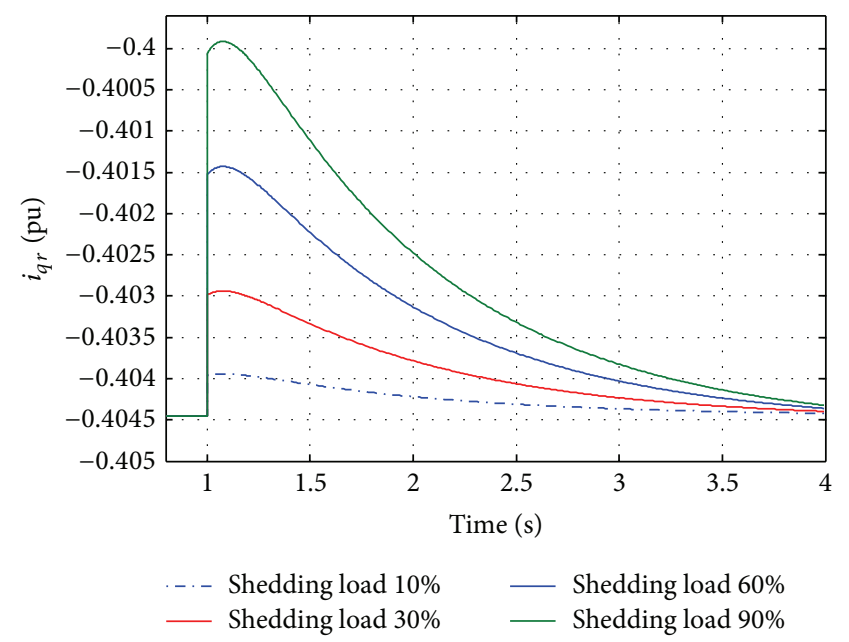

FIGURE 14: The rotor current curve of a DFIG in the quadrature axis under different load shedding proportion.

affected, namely, the chattering in the system increasing. When $\alpha=500$, the system adjusting speed is slow, and the chattering of control law is also serious. As shown in Figures 15-17, this controller has strong robustness, and the changes of state variables caused by parameter perturbations can be controlled in reasonable level range.

In addition, when $\beta$ is 5,150 , and 200 , respectively, the situation is shown in Figure 16. As shown in Figure 16, the larger the $\beta$, the faster the adjusting speed for current.

It is proved that the ranges of $\beta$ are $40 \sim 5000$ in this paper, by a lot of simulation experiments. Within the limitation of parameters, it has a good performance when the larger parameters are adopted. With parameter variation increasing, the transient pulse value is small. However, the parameters must be restricted. If the parameters exceed limitation, it could lead to instability for power system. So the proper parameters should be selected. In this paper, $\beta=50$

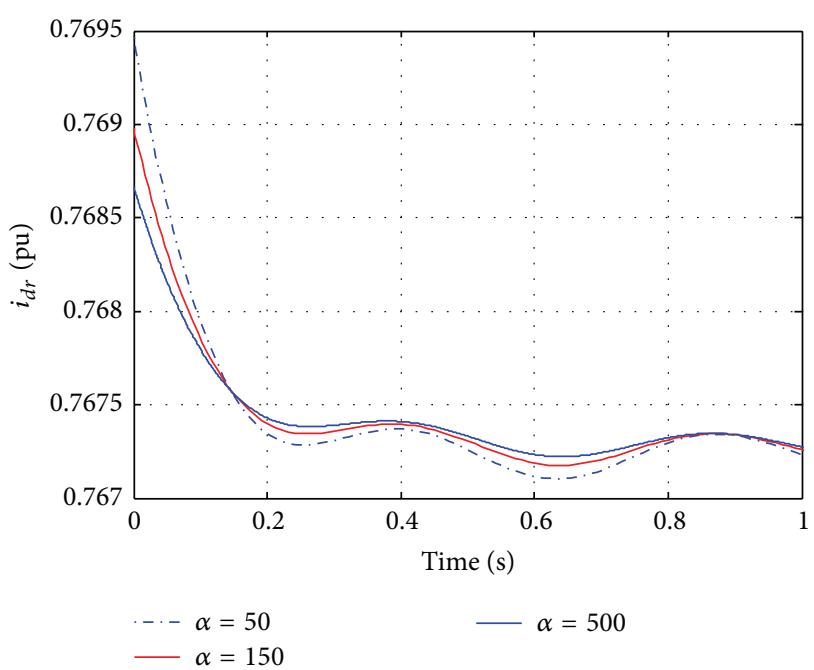

FIGURE 15: The rotor current curve of a DFIG in the direct axis under different $\alpha$.

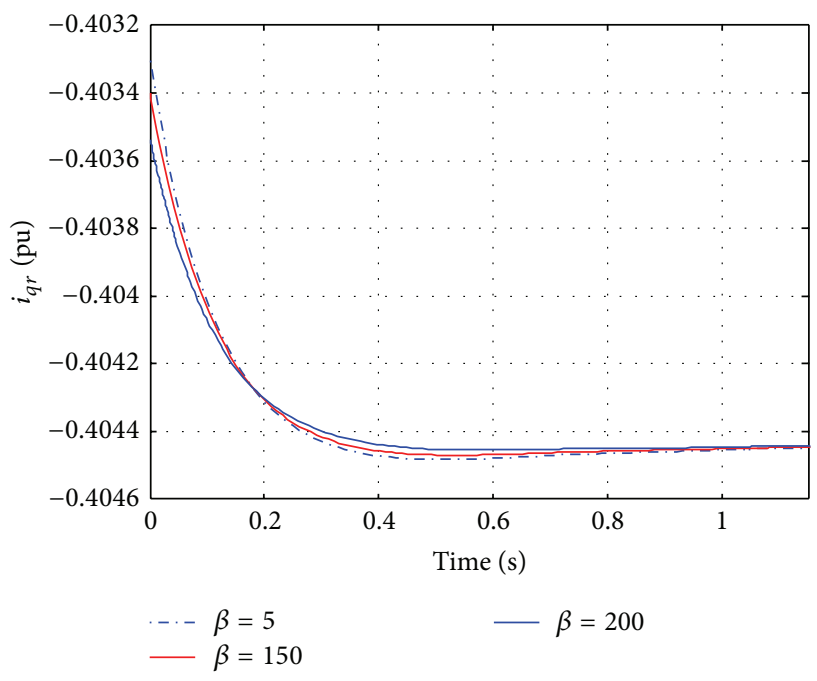

FIGURE 16: The rotor current curve of a DFIG in the quadrature axis under different $\beta$.

are selected in the experiment. So the best results can be obtained, and the test curves are shown in the Figures 5-12.

As shown in Figure 17, the larger the $c_{1}$, the faster the adjusting speed for current in general. When $c_{1}=5$, the system adjusting speed is slow, and the chattering of control law is also serious.

\section{Conclusions}

The nonlinear rotor current controller is introduced in this paper, which is designed by combining the advantages of ESO and terminal SMC theory. It enhances FRT capabilities of DFIG-based wind power generation system. ESO compensates internal and external disturbances of system dynamically and it has reduced the complexity of the controller and with strong practicability and robustness. Terminal 


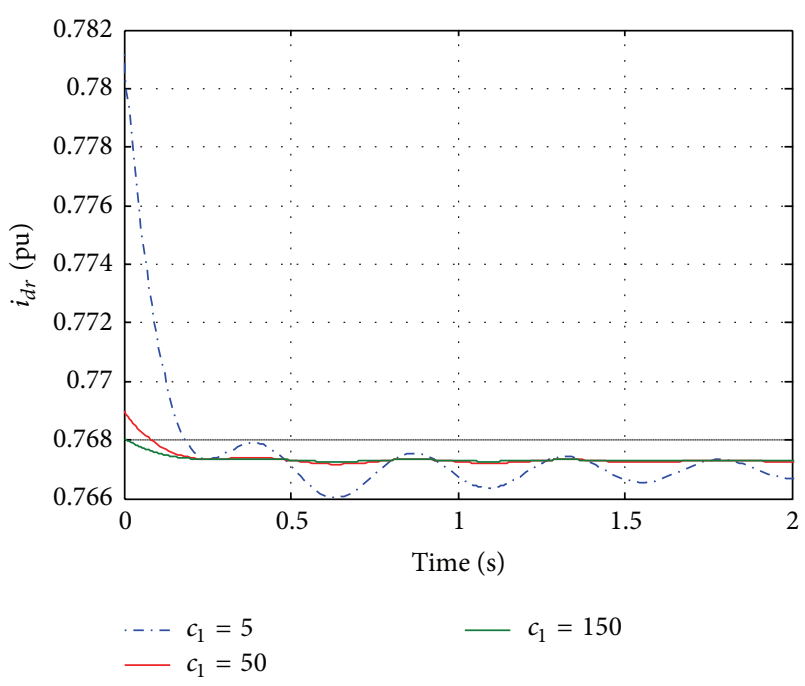

FIGURE 17: The rotor current curve of a DFIG in the direct axis under different $c_{1}$.

sliding mode makes a design of controllers to simplify and improve the convergence speed. ESO-terminal SMC has the advantages of rapid response and insensitive for disturbances. A nonlinear rotor current control law with good robustness and better dynamic quality is obtained. The proposed ESOterminal SMC has very fast transient response that will effectively eliminate the overcurrent in the rotor side converter and limit electromagnetic torque in the DFIG fluctuations, with strong adaptability. Simulation results show that the proposed rotor current control scheme enables the DFIG to successfully comply with FRT regulations. The proposed control method is easy to be realized in engineering.

\section{Conflict of Interests}

The authors declare that there is no conflict of interests regarding the publication of this paper.

\section{Acknowledgments}

The authors gratefully acknowledge the support of National Natural Science Foundation of China (no. 51377017) and Changjiang Scholars and Innovative Research Team in University (IRT1114).

\section{References}

[1] J. B. Ekanayake, L. Holdsworth, X. Wu, and N. Jenkins, "Dynamic modeling of doubly fed induction generator wind turbines," IEEE Transactions on Power Systems, vol. 18, no. 2, pp. 803-809, 2003.

[2] M. M. Kyaw and V. K. Ramachandaramurthy, "Fault ride through and voltage regulation for grid connected wind turbine," Renewable Energy, vol. 36, no. 1, pp. 206-215, 2011.

[3] M. Mohseni, M. A. S. Masoum, and S. M. Islam, "Low and high voltage ride-through of DFIG wind turbines using hybrid current controlled converters," Electric Power Systems Research, vol. 81, no. 7, pp. 1456-1465, 2011.

[4] N. R. Ullah, T. Thiringer, and D. Karlsson, "Voltage and transient stability support by wind farms complying with the E.ON netz grid code," IEEE Transactions on Power Systems, vol. 22, no. 4, pp. 1647-1656, 2007.

[5] P. S. Flannery and G. Venkataramanan, "A fault tolerant doubly fed induction generator wind turbine using a parallel grid side rectifier and series grid side converter," IEEE Transactions on Power Electronics, vol. 23, no. 3, pp. 1126-1135, 2008.

[6] J. Yang, J. E. Fletcher, and J. O’Reilly, “A series-dynamic-resistorbased converter protection scheme for doubly-fed induction generator during various fault conditions," IEEE Transactions on Energy Conversion, vol. 25, no. 2, pp. 422-432, 2010.

[7] D. Kairous and R. Wamkeue, "DFIG-based fuzzy sliding-mode control of WECS with a flywheel energy storage," Electric Power Systems Research, vol. 93, pp. 16-23, 2012.

[8] L. S. Barros, W. S. Mota, L. G. Q. Silveira, and P. S. Oliveira, "DFIG rotor side control through gain-scheduling designed by genetic algorithm," in Proceedings of the 6th IEEE/PES Transmission and Distribution: Latin America Conference and Exposition (T\&D-LA), pp. 1-6, Orlando, Fla, USA, May 2012.

[9] B. Beltran, T. Ahmed-Ali, and M. E. H. Benbouzid, "High-order sliding-mode control of variable-speed wind turbines," IEEE Transactions on Industrial Electronics, vol. 56, no. 9, pp. 33143321, 2009.

[10] M. I. Martinez, G. Tapia, A. Susperregui, and H. Camblong, "Sliding-mode control for DFIG rotor- and grid-side converters under unbalanced and harmonically distorted grid voltage," IEEE Transactions on Energy Conversion, vol. 27, no. 2, pp. 328339, 2012.

[11] J. Hu, Y. He, and L. Xu, "Improved rotor current control of wind turbine driven doubly-fed induction generators during network voltage unbalance," Electric Power Systems Research, vol. 80, no. 7, pp. 847-856, 2010.

[12] C. W. Tao, J. S. Taur, and M.-L. Chan, "Adaptive fuzzy terminal sliding mode controller for linear systems with mismatched time-varying uncertainties," IEEE Transactions on Systems, Man, and Cybernetics B, vol. 34, no. 1, pp. 255-262, 2004.

[13] J. Liu, Matlab Simulation for Sliding Mode Control, Tsinghua University Press, Beijing, China, 2005.

[14] J. Han, Active Disturbance Rejection Control Technique, National Defense Industry Press, Beijing, China, 2008.

[15] J. Han, "From PID to active disturbance rejection control," IEEE Transactions on Industrial Electronics, vol. 56, no. 3, pp. 900906, 2009.

[16] S. He and F. Liu, "Finite-time $H_{\infty}$ control of nonlinear jump systems with time-delays via dynamic observer-based state feedback," IEEE Transactions on Fuzzy Systems, vol. 20, no. 4, pp. 605-614, 2012.

[17] S. He and F. Liu, "Robust $L_{2}-L_{\infty}$ filtering of time-delay jump systems with respect to the finite-time interval," Mathematical Problems in Engineering, vol. 2011, Article ID 839648, 17 pages, 2011.

[18] J. Hu, Y. He, L. Xu, and B. W. Williams, "Improved control of DFIG systems during network unbalance using PI-R current regulators," IEEE Transactions on Industrial Electronics, vol. 56, no. 2, pp. 439-451, 2009. 
[19] Y. Feng, X. Yu, and F. Han, "High-order terminal slidingmode observer for parameter estimation of a permanentmagnet synchronous motor," IEEE Transactions on Industrial Electronics, vol. 60, no. 10, pp. 4272-4280, 2013.

[20] M. Mohseni, S. M. Islam, and M. A. S. Masoum, "Enhanced hysteresis-based current regulators in vector control of DFIG wind turbines," IEEE Transactions on Power Electronics, vol. 26, no. 1, pp. 223-234, 2011. 


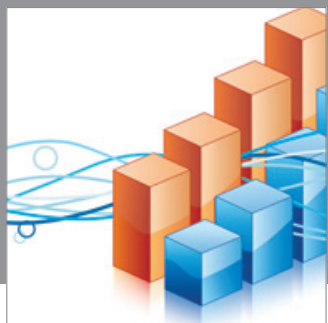

Advances in

Operations Research

mansans

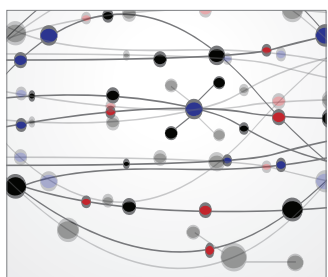

The Scientific World Journal
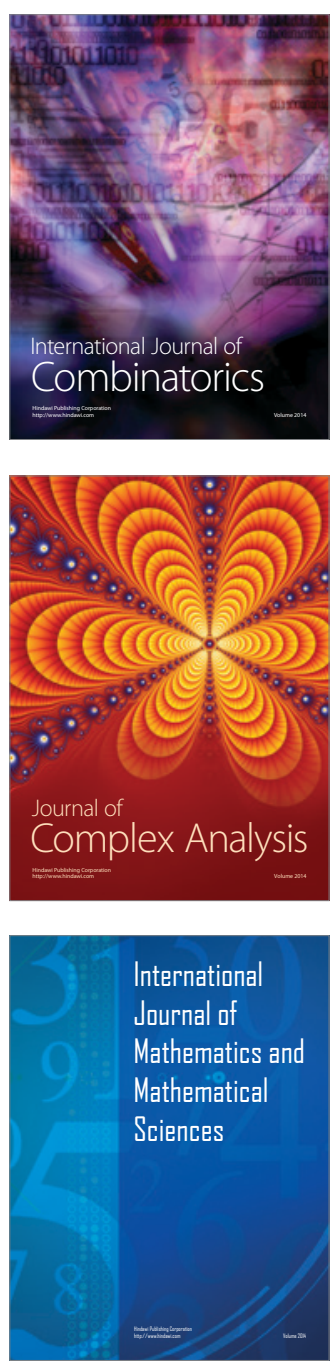
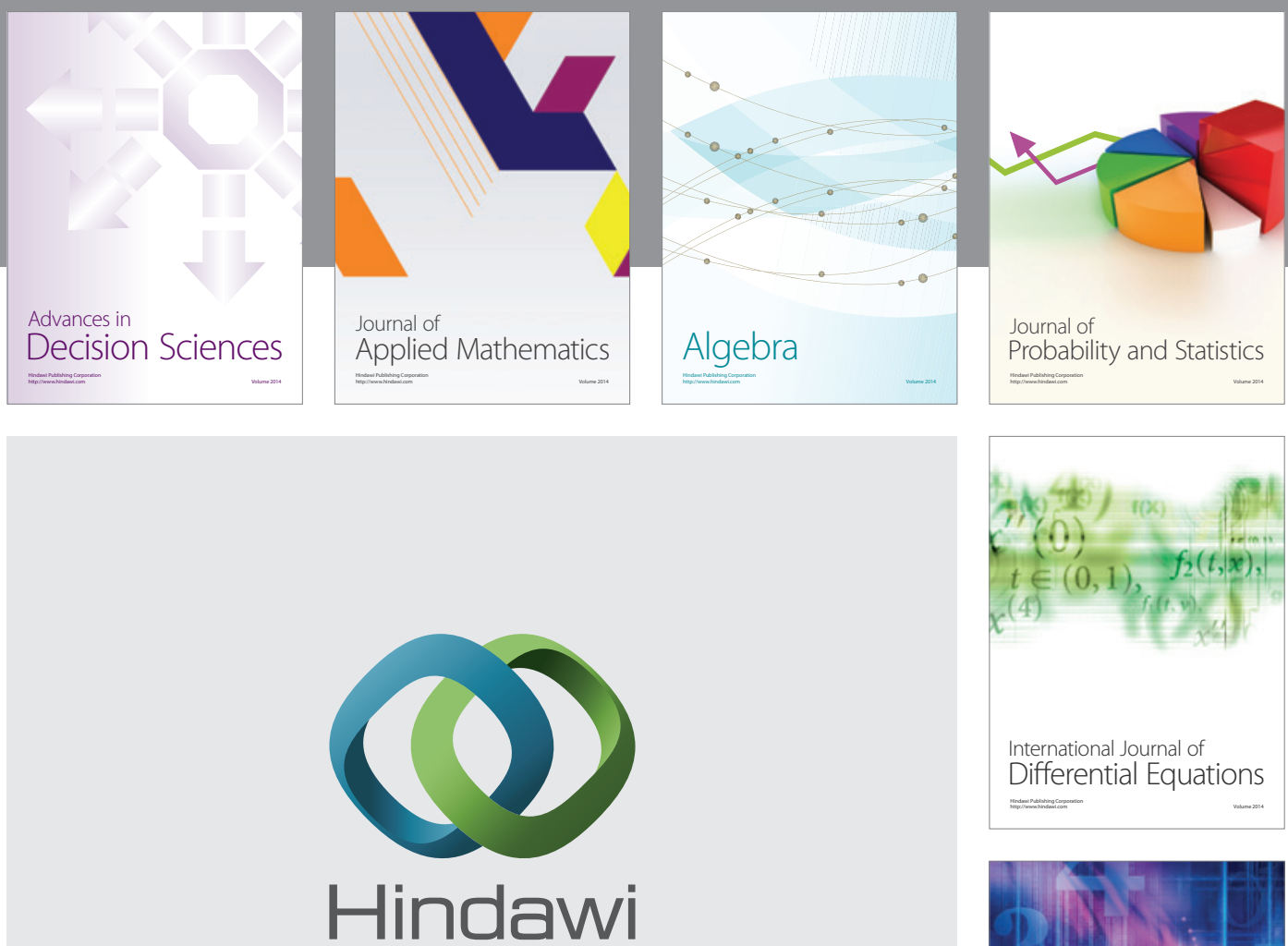

Submit your manuscripts at http://www.hindawi.com
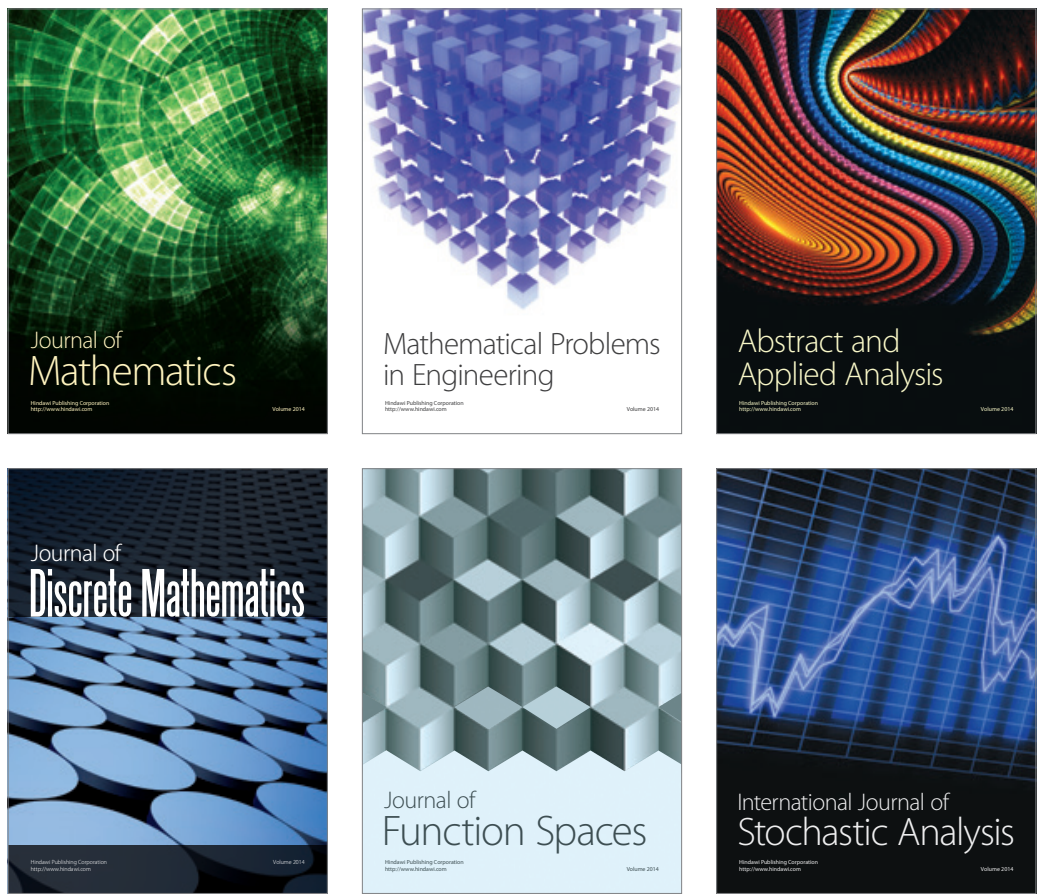

Journal of

Function Spaces

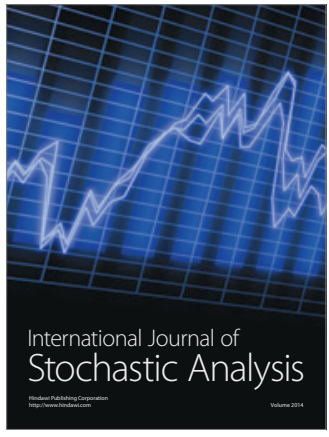

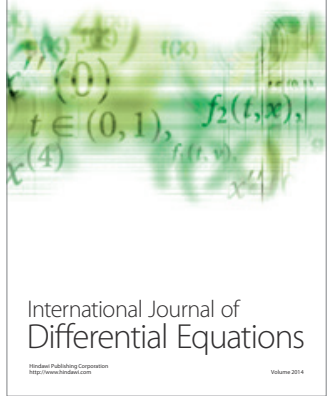
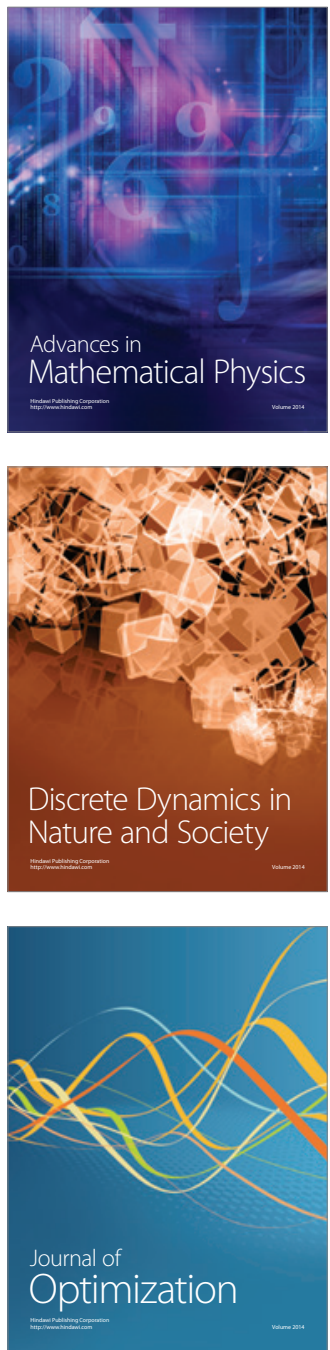